\title{
Carbetocin Versus Oxytocin for Prophylaxis of PPH Used During Caesarean Section: An Open Label Randomized Control Trial
}

\author{
NAHAER MK ${ }^{1}$, NURUNNOBI AKM ${ }^{2}$, TALUKDER SI $^{3}$, FERDOUSY $\mathrm{H}^{4}$, \\ SHARMIN F, ISLAM GMR ${ }^{6}$, PARVIN R $^{7}$
}

\begin{abstract}
Background: Postpartum hemorrhage is the leading cause of maternal mortality; uterine atony is the most important cause. Uterotonics are used to prevent uterine atony. Carbetocin, a synthetic anallague of oxytocin seems to be an effective and safe new drug for prevention of PPH after caesarean

The Aim of Study: To find out the efficacy and safety of carbetocin over oxytocin for the prevention of PPH during caesarean section.

Patients and Methods: A randomized-controlled trial was conducted in the Dept. of Obs \& Gyane, Rangpur Medical College and Hospital, Rangpur, Bangladesh over a period of twelve months from June 2016 to June 2017. One hundred admitted patients undergoing cesarean section at term were randomized into two groups receiving either $10 \mathrm{IU}$ oxytocin or $100 \mu \mathrm{g}$ carbetocin after caesarean section. Outcome measures such as primary PPH, massive blood loss, need for additional uterotonic drug, additional blood transfusion as well as adverse effects were all documented.

Results: Massive blood loss occurred in $6 \%$ patients, blood transfusion needed in $20 \%$ patients and additional uterotonic needed for $36 \%$ patients in Oxytocin group but in Carbetocin group no massive blood lossoccurred, only 2\%patients needed immediate blood transfusion and $4 \%$ patients were required additional uterotonics. There were no major adverse effects observed in both the groups. No patients had developed PPH in carbetocin group. But 8\%(4) patients had developed PPH in oxytocin group.

Conclusion: Carbetocin appears to be an effective new drug than Oxytocin for the prevention of postpartum hemorrhage following caesarean section.
\end{abstract}

Key Words: Carbetocin, Oxytocin, Postpartum hemorrhage.

Introduction:

PPH complicates $11 \%$ of deliveries worldwide and is annually responsible for $1,32,000$ maternal deaths ${ }^{1}$. In low income setting, PPH accounting for $30 \%$ of maternal death ${ }^{2}$, while in Bangladesh it is
$31 \%^{3}$. All pregnant women are at risk of complications during the $3^{\text {rd }}$ stage of labor ${ }^{4}$. For women undergoing delivery by cesarean section, there is an increased risk of postpartum hemorrhage compared to vaginal delivery ${ }^{5}$. Primary PPH is the most common obstetric

1. Associate Professor,, Department of Gynecology and Obstetrics, Rangpur Medical College and Hospital, Bangladesh

2. Department of Dermatology and Venerology,Rangpur Medical College and Hospital, Bangladesh

3. Assistant Professor, Department of Anaesthesiology, Rangpur Medical College and Hospital, Bangladesh

4. Junior Consultant, Department of Gynecology and Obstetrics, Rangpur Medical College and Hospital, Bangladesh.

5. Asst. Register,Department of Gynecology and Obstetrics,Rangpur Medical College and Hospital, Bangladesh.

6. Senior Manager, Medical Services Department, Beacon Pharmaceuticals Ltd.

7. Dr. Rehana Parvin, MBBS

Address of Correspondence: Dr. Mst. Kamrun Nahaer, Associate Professor, Department of Gynecology and Obstetrics, Rangpur Medical College and Hospital. Email: knahaer123@gmail.com, Mobile: 01713365520 
hemorrhage and is defined by the World Health Organization as the loss of blood estimated to be $>1000 \mathrm{ml}$ from the genital tract aftercaesarean section within 24 hoursofdelivery 6 .If obstetric hemorrhage is not managed efficiently and effectively, this will lead to shock, haemostatic failure from disseminated intravascular coagulation and ultimately death ${ }^{7}$. So, use of an effective uterotonic drug for prevention of uterine atony is highly recommended.Conventional uterotonics like oxytocin has been used for preventing PPH but it has some limitations like shorter half- life ${ }^{8}$, less contraction time and more side effects like fluid overload, convulsion, arrhythmia and pulmonary edema. On the other hand the ergot alkaloids cannot be used in $10-15 \%$ of women who have gestational hypertension ${ }^{9}$. Further, oxytocin and ergot preparation require protection against light to preserve its effectiveness and stability ${ }^{10}$.

In our country cold chain is not properly maintained for oxytocin. So, there is a chance of its effectiveness and stability problems. As a result, treatment failure may occur. Bleeding due to uterine atony, can be prevented by an effective uterotonic agent ${ }^{11}$. Till now it is recommended that oxytocin should be used as uterotonic agent either in the form of intramuscular injection or intravenous infusion.

Carbetocin has prolonged duration of action (approximately 1 hour) which ensures more contraction time and less adverse effect ${ }^{12,13}$. The clinical and pharmacological properties of carbetocin are similar to those of naturally occurring oxytocin. Carbetocin binds to oxytocin receptors present on the smooth musculature of the uterus, resulting in rhythmic contractions of the uterus, increased frequency of existing contractions and increased uterine tone ${ }^{10}$.A single dose of carbetocin has been hypothesis to act upto 16 hours in comparison to intravenous oxytocin infusion regarding the increase in uterine tone and the reduction of the risk of PPH in caesarean section ${ }^{12}$.Moreover, carbetocin ensures more effective contraction and less adverse effect likeheadache, tremor, hypotension, nausea, abdominal pain, and pruritus ${ }^{9}$. Several data of literature suggest that prophylactic administration of carbetocin may be a good alternative to oxytocin to prevent post-partum hemorrhage ${ }^{14}$. We had conducted this clinical study to evaluate the efficacy and safety of Carbetocin for the prevention of PPH during caesarian section.

\section{Materials and Methods}

This randomized control trial was conducted on 100 admitted pregnant women from June'2016 to June'2017 in the Department of Gynecology and Obstetrics, Rangpur Medical College Hospital, Rangpur, Bangladesh. The participants were enrolled in the study after fulfilling the inclusion and exclusion criteria. According to computer generated randomization sequential number was allocated for the cases. A written informed consent was taken from eligible women on admission. The study protocol was approved by the ethical committee of Rangpur Medical College Hospital, Rangpur, Bangladesh.

Inclusion criteria were women with a single pregnancy undergoing caesarean delivery. Exclusion criteria were placenta previa, multiple gestation, placental abruption (determined by history and ultrasound report) hypertensive disorders in pregnancy, preeclampsia, and known case of cardiac, renal, liver diseases, epilepsy, moderate anemia and unwilling to participate in the study.

During the study period 50 women were enrolled who received Carbetocin $100 \mu \mathrm{g} \mathrm{I} / \mathrm{V}$ as a single dose and 50 women who received 10 IU of oxytocin after caesarean section. The primary outcome was measured by the amount of blood loss within 24 hours after delivery.

Blood loss was estimated by the surgeon in the usual way (visual estimation, number of used sanitary pad and amount of aspirated blood).

The secondary outcomes were massive blood loss, need for additional uterotonic drug, additional blood transfusion as well as adverse effects within 24 hours of delivery. Uterine tone was evaluated by palpation and administration of additional uterotonics was the decision of the investigator.

\section{Statistical Analysis:}

Analysis was performed by using a computer based statistical program SPSS (Statistical Package for Social Sciences) version 23. Quantitative data were expressed as means \pm SD. 95\% confidence interval was calculated and $p$ value of $<0.05$ was considered as significant.

\section{Result:}

A total of 111 pregnant women with a single pregnancy were initially recruited for inclusion in this study; 11 cases were excluded (4 had pre-eclampsia, 
2 eclampsia, 3 multiple gestation, 2 severely anemic). Thus 100 women formed the final study group and were included in the final analysis. Mean age of study population were $25.2 \pm 3.9$ in carbetocin group and $24.9 \pm 5.3$ in oxytocin group (Table I). Among the study patients $88 \%$ (44) had mild anemia in Carbetocin group and 84\% (42) had mild anemia in oxytocin group. Mean systolic BP of patients were $116 \pm 9.5 \mathrm{~mm}$ of $\mathrm{Hg}$ and Diastolic BP were $75 \pm 1.8 \mathrm{~mm}$ of $\mathrm{Hg}$ in Carbetocin group and mean systolic BP were $118 \pm 1.3 \mathrm{~mm}$ of $\mathrm{Hg}$ and Diastolic BP were $77.7 \pm 1.3 \mathrm{~mm}$ of $\mathrm{Hg}$ in Oxytocin group. Mean gestational age at delivery were $36.9 \pm 5.4$ in Carbetocin group and 38 5.4 in Oxytocin group (Table-I). Massive blood loss occurred in $6 \%$ patients, blood transfusion needed in $20 \%$ patients and additional uterotonic needed for $36 \%$ patients in Oxytocin group but in Carbetocin group no massive blood lossoccured, only $2 \%$ patients needed immediate blood transfusion and $4 \%$ patients were required additional uterotonics (Table-II). There were no major adverse effects observed in both the groups (Table-III). No patients had developed PPH in carbetocin group. But $8 \%$ (4) patients had developed $\mathrm{PPH}$ in oxytocin group. (Table-IV)

Table-2.Shows that massive blood loss occurred in $6.0 \%$ patients, blood transfusion needed for $20 \%$ patients and additional uterotonic drug needed for $36.0 \%$ patients in Oxytocin group but in carbetocin group no massive blood lossoccurred and blood transfusion needed only $2.0 \%$ patients and $4.0 \%$ patient was required additional uterotonics. The mean differences were statistically significant $(P<0.05)$.

Table- IV. Showed no patients had developed PPH in carbetocin group. But $8 \%$ (4) patients had developed $\mathrm{PPH}$ in oxytocin group. The mean differences were statistically significant $(P<0.05)$.

Table-I

Distribution of study subjects according to Baseline characteristics $(n=100)$

\begin{tabular}{lccc}
\hline & Carbetocin Group (50) & Oxytocin Group (50) & P value \\
\hline Age & $25.2 \pm 3.9$ & $24.9 \pm 5.3$ & 0.31 \\
Mild Anemia & $88 \%(44)$ & $84 \%(42)$ & 0.31 \\
Systolic BP & $116 \pm 9.5 \mathrm{~mm}$ of Hg & $118 \pm 1.3$ & 0.21 \\
Diastolic BP & $75 \pm 1.8 \mathrm{~mm}$ of Hg & $77.9 \pm 1.3 \mathrm{~mm}$ of Hg & 0.50 \\
Gestational Age & $36.9 \pm 5.4$ weeks & $38 \pm 5.4$ weeks & 0.79 \\
\hline
\end{tabular}

(Students "t" test)

Table-II

Distribution of study subjects according to Outcome of Labour ( $n=100)$

\begin{tabular}{lccccc}
\hline Outcome during Labour & Carbetocin & Group (50) & Oxytocin & Group(50) & P value \\
& Yes (\%) & No (\%) & Yes (\%) & No (\%) & \\
\hline Massive blood loss & $00 \%$ & $100 \%$ & $6.0 \%(3)$ & $94.0 \%(47)$ & 0.001 \\
Blood transfusion & $2.0 \%(1)$ & $98.0 \%(49)$ & $20 \%(10)$ & $80.0 \%(40)$ & 0.001 \\
Need for additional uterotonics & $4.0 \%(2)$ & $96 \%(48)$ & $36.0 \%(18)$ & $64.0 \%(32)$ & 0.001 \\
\hline
\end{tabular}

(Students "t" test)

Table-III

Distribution of study subjects according to Adverse effects ( $n=100)$

\begin{tabular}{lccc}
\hline Side effects & Carbetocin $(\mathrm{n}=50) \mathrm{n}(\%)$ & Oxytocin $(\mathrm{n}=50) \mathrm{n}(\%)$ & $\mathrm{P}$ value \\
\hline Nausea & $2.0 \%(1)$ & $4.0 \%(2)$ & 0.25 \\
Vomiting & $2.0 \%(1)$ & $6.0 \%(3)$ & 0.75 \\
Fever & $00 \%(0)$ & $6.0 \%(3)$ & 0.33 \\
Arrhythmia & $00 \%(0)$ & $2.0 \%(0)$ & 0.30 \\
Pulmonary edema & $00 \%(0)$ & $00 \%(0)$ & 0.50 \\
Abdominal Pain & $00 \%(0)$ & $6.0 \%(3)$ & 0.33 \\
Headache & $00 \%(0)$ & $6.0 \%(3)$ & 0.33 \\
Tremor & $00 \%(0)$ & $00 \%(0)$ & 0.50 \\
Hypotension & $00 \%(0)$ & $00 \%(0)$ & 0.50 \\
Pruritus & $00 \%(0)$ & $00 \%(0)$ & 0.50 \\
\hline
\end{tabular}


Table-IV

Distribution of study subjects according to Outcome of the patient: Primary PPH $(n=100)$

\begin{tabular}{lccc}
\hline Outcome ( Primary PPH) & Carbetocin group (50) & Oxytocin group (50) & P Value \\
\hline Yes & $0(0.0)$ & $8.0 \%(4)$ & 0.001 \\
No & $50(100)$ & $92.0 \%(46)$ & \\
\hline
\end{tabular}

\section{Discussion:}

The results of this study had shown that carbetocin is superior in comparison to oxytocin for the prevention of $\mathrm{PPH}$ following ceaserian section. Each patient obtained a single dose of 100 microgram carbetocin intravenously during cesarean section, immediately after the delivery of the baby and prior to the delivery of the placenta. Outcome measures such as primary PPH, massive blood loss, need for additional uterotonic drug, additional blood transfusion as well as adverse effects were documented.

Reyes OA and Gonzalez GM et al. ${ }^{15}$ showed that mean age of study patient in carbetocin group were 26.5 years and 26.7 years in oxytocin group. In this study mean age of study patients were 25.2 years incarbetocin group and 24.9 years in oxytocin group. Debbie-lynuy and Nelindacatherinep et al. ${ }^{16}$ showed that mean preoperative systolic BP of study patients in carbetocin group were $117 \pm 6.8 \mathrm{~mm}$ of $\mathrm{Hg}$ and diastolic BP were $69 \pm 7.7 \mathrm{~mm}$ of $\mathrm{Hg}$ and mean preoperative systolic BP were $118 \pm 8.3 \mathrm{~mm}$ of $\mathrm{Hg}$ and diastolic BP were $73 \pm 8.5 \mathrm{~mm}$ of $\mathrm{Hg}$ in Oxytocin group. In this study, mean preoperative systolic BP of patients were $116 \pm 9.5 \mathrm{~mm}$ of $\mathrm{Hg}$ and diastolic BP were $75 \pm 1.8 \mathrm{~mm}$ of $\mathrm{Hg}$ in carbetocin group and mean systolic BP were $118 \pm 1.3 \mathrm{~mm}$ of $\mathrm{Hg}$ and diastolic BP were $77.9 \pm 1.3 \mathrm{~mm}$ of $\mathrm{Hg}$ in oxytocin group. All patients of both the groups were with normal blood pressure.

Reyes OA and Gonzalez GM et al ${ }^{15}$ also showed that the mean gestational age of study patient in carbetocin group were 37.44 weeks and 36.93 weeks in oxytocin group which is almost similar to this study; $36.9 \pm 5.4$ weeks in Carbetocin group and $38 \pm 5.4$ weeks in oxytocin group. They also showed that there was no significant difference between the two study groups regarding occurrence of adverse effects of both the drugs. In this study, there were no major adverse effects observed in both the groups.

Manal M. E Behery et al. ${ }^{17}$ showed that none of women in carbetocin group required blood transfusion, while $15.5 \%$ in oxytocin group required blood transfusion. In this study, only $2 \%(1)$ patient in carbetocin group was needed blood transfusion but in oxytocin group blood transfusion were required for $20 \%$ patients.

Sergio Rosales-Ortiz, Rogelio Perez Aguado et al. ${ }^{18}$ showed that only $1.5 \%$ patients need additional uterotonics in carbetocin group and $5.8 \%$ patients in oxytocin group. Manal M. E Behery et al. ${ }^{17}$ showed that none of the patient in carbetocin group required additional uterotonics while as high as $71.5 \%$ of women in oxytocin group needed additional oxytocin to ensure adequate uterine contraction for long period. CAG. Holleboom, J. van Eyck et al. ${ }^{19}$ also showed the comparison between carbetocin with oxytocin, prophylaxis of uterine atony with carbetocin after an elective caesarean section diminished the need for additional uterotonics by more than $50 \%$ in oxytocin group. Debbie-lynuy et al. ${ }^{16}$ showed that only $5.7 \%$ patients were need for additional uterotonics in carbetocin group and $34.3 \%$ patients in oxytocin group. In this study, $4 \%$ patients of carbetocin group were required additional uterotonic but in oxytocin group additional uterotonics were required for $36 \%$ patients.

Ahmed Mohamed Maged et al. ${ }^{20}$ also showed the occurrence of $\mathrm{PPH}$ were $4 \%$ in carbetocin group and $16 \%$ in oxytocin group. In this study, occurrence of $\mathrm{PPH}$ in oxytocin group was $8 \%$ patients but in carbetocin group none of patients had developed $\mathrm{PPH}$.

Primary postpartum hemorrhage (PPH) is the most common form of major obstetric hemorrhage ${ }^{21}$. It is the most common cause of maternal morbidity in developed countries and a major cause of death worldwide 22,23 . The most common point at which $\mathrm{PPH}$ occurs is during the third stage of labour, when the uterus may suddenly loss its ability to contract. Around $80 \%$ of cases of postpartum hemorrhage occur due to uterine atony ${ }^{24}$. Bleeding due to uterine atony, can be prevented by an effective uterotonic drug $^{25}$. The promising findings suggested that 
carbetocin appears to be an effective new drug for the prevention of PPH in caesarian delivery. A single dose of 100 microgram IV carbetocin is more effective than oxytocin for maintaining adequate uterine tone, decreases blood loss and preventing postpartum hemorrhage in women undergoing caesarian delivery. Carbetocincan be considered as a good uterotonic agent over Oxytocin for the prevention of $\mathrm{PPH}$ in caesarian section.

\section{Acknowledgments:}

This study was conducted by Department of Gynecology \& Obstetrics, Rangpur Medical College and Hospital,Rangpur, Bangladesh. The preparation of Carbetocin was Duratocin manufactured by Beacon Pharmaceuticals Limited, Bangladesh. The research team would like to thank all doctors, health staff and patients for participating in the clinical trial.

\section{Conflict of interest:}

The authors declare that there is no conflict of interests regarding the clinical trial.

\section{References:}

1. Carroli G,Cuesta C, Abalos E, and Gulmezoglu A.M. Epidemiology of postpartum haemorrhage: A systematic review.Best.Pract. Res. Clin. Obstet. Gynaecol., 22 (6): 999-1012, 2008

2. Derman R, Kodkany BS, Goudar SS, Geller SE, Naik VA, Bellad MB, Patted SS, Patel A, Edlavitch SA, Hartwell T, Chakraborty H, Moss N.Oral misoprostol in preventing postpartumhaemorrhage in resource-poor communities: a randomised controlled trial. Lancet2006; 368:1248-53.

3. National Institute of Population Research and Training (NIPORT), MEASURE Evaluation, UNC-CH, USA, ICDDR, B., 2011

4. Smith JR. Management of Third Stage of Labor: January 6, 2012

5. Prendiville $W$ and Connell MO. Active management of the third stage of labor p. 98113

6. World Health Organisation: WHO Guidelines for the Management of Postpartum Haemorrhage and Retained Placenta. http://whqlibdoc.who.int/ publications/2009/ 9789241598514_eng. pdf, 2009
7. Annette Briley and Susan Bewle: Management of obstetric haemorrhage. In: Sue Pavrod and Beverly Hunt. The Obstetric Hematology Manual. United State of America, Cambridge University Press, ISBN-13 978-0-521-86564- 7, Section 5 Chapter 13a, 2010.

8. Oyelese Y, Scorza WE, Mastrolia R, SmulianJC .Post- partum hemorrhage. Obstet Gynecol Clin N Am 2007; 34(3):421-441.

9. G Larciprete, C Montagnoli, M Frigo, V Panetta $\mathrm{J}$, Prenat et al Carbetocin versus oxytocin in caesarean section with high risk of post-partum haemorrhage Med. 2013 Jan-Mar; 7(1): 12-18.

10. Werner R. Prevention of postpartum haemorrhage with the oxytocin analogue carbetocin. European Journal of Obstetrics and Gynecology and Reproductive Biology; 2009; 147 (1): 15-20.

11. Derman R, Kodkany BS, Goudar SS, Geller SE, Naik VA, Bellad MB, Patted SS, Patel A, Edlavitch SA, Hartwell T, Chakraborty H, Moss N.Oral misoprostol in preventing post partumhaemorrhage in resource-poor communities: a randomised controlled trial. Lancet2006; 368:1248-53.

12. Tharakan T, Jha J Randomized double blind prospective trial of active management of the third stage of labor. Arch Med Sci 2008; 4(1): 79-82.

13. Sergio RO, RP Aguado et al. Carbetocin versus oxytocin for prevention of postpartum haemorrhage: a randomized controlled trial. Published Online February 26, 2014 School of Clinical and Experimental Medicine, University of Birmingham, UK

14. MP Yuen.Oxytocic Agents for the Management of Postpartum Haemorrhage 2011; 16: 10.

15. Reyes OA, Gonzalez GM :Carbetocin versus oxytocin for prevention of postpartum hemorrhage in patients with severe preeclampsia: a double-blind randomized controlled trial. J obstetgynaecol can 2011; 33(11):1099-1104

16. D lynuy, NAtherinep et al: Carbetocin versus Oxytocin for the Prevention of Postpartum Hemorrhage Following Elective Cesarean Section: Rizal Medical Center Experience; 
Philippine Journal of Obstetrics \& Gynecology. 2013; 37 (2):71-79

17. Manal M, El Behery, GAbbas, El Sayeda, Azza A et al: Carbetocin versus oxytocin for prevention of postpartum hemorrhage in obese nulliparous women undergoing emergency cesarean delivery.

18. S R Ortiz, R P Aguado, RS Hernandez, M Castorena et al: Carbetocin versus oxytocin for prevention of postpartum haemorrhage: a randomised controlled trial; The Lancet. 2014 ;383:51

19. CAG. Holleboom, J.VAN Eyck, SV. Koenen: Carbetocin in comparison with oxytocin in several dosing regimens for the prevention of uterine atony after elective caesarean section in the Netherlands. ArchGynecolObstet 2013; 287:1111-1117

20. AM Maged, A Gany, A Hassan, AA Nesreen\& Shehata: Carbetocin versus oxytocin for prevention of postpartum hemorrhage after vaginal delivery in high risk women; $\mathrm{J}$ Matern Fetal Neonatal Med,2015; 29(4): 532-536
21. Prevention and management of postpartum haemorrhage, Royal College of Obstetricians and Gynaecologists, Green-top Guideline No. 52, Minor revisions November 2009 and April 2011

22. The Prevention and Management of Postpartum Haemorrhage: Report of Technical Working Group, Geneva 3-6 July 1989. Geneva: World Health Organization, 1990

23. Bais JM, Eskes M, Pel M, Bonsel GJ, Bleker OP. Postpartum haemorrhage in nulliparous women: incidence and risk factors in low and high risk women. A Dutch population-based cohort study .Eur J ObstetGynecolReprod Biol. 2004; 115:166-72

24. Dutch Association of Obstetrics and Gynaecology (NVOG) .Guideline postpartum haemorrhage. 2012;1-9.

25. Chandhiok N, Dhillon BS, Datey S, Mathur A, Saxena NC .Oral misoprostol for prevention of postpartum haemorrhage by paramedical workers in India. Int J GynaecolObstet 2006; 92:170-75 